
Table 1. Relation Between the DaY-Age and THE NUMBER OF Stripe-

\begin{tabular}{|c|c|c|c|c|c|c|}
\hline \multirow{2}{*}{ Species } & \multirow{2}{*}{$\begin{array}{l}\text { No. of } \\
\text { speci- } \\
\text { mens }\end{array}$} & \multirow{2}{*}{$\begin{array}{c}\text { Days } \\
\text { after } \\
\text { hatching }\end{array}$} & \multicolumn{2}{|c|}{ Shell-length $(\mathrm{mm})$} & \multicolumn{2}{|c|}{ No. of stripe-line } \\
\hline & & & Range & Mean & Range & Mean \\
\hline $\begin{array}{l}\text { Sepia } \\
\text { escul- } \\
\text { enta }\end{array}$ & $\begin{array}{r}12 \\
12 \\
1 \\
5 \\
3 \\
11 \\
5 \\
2 \\
3\end{array}$ & $\begin{array}{c}0 \\
18-19 \\
23 \\
24 \\
26 \\
29-30 \\
32-33 \\
35 \\
37-40\end{array}$ & $\begin{array}{r}3 \cdot 59-5 \cdot 04 \\
9 \cdot 4-12 \cdot 4 \\
14 \cdot 0 \\
14 \cdot 0-16 \cdot 0 \\
15 \cdot 5-18 \cdot 0 \\
18 \cdot 0-24 \cdot 0 \\
21 \cdot 2-24 \cdot 2 \\
21 \cdot 0-21 \cdot 3 \\
22 \cdot 6-24 \cdot 2\end{array}$ & $\begin{array}{c}4 \cdot 33 \\
11 \cdot 1 \\
14 \cdot 0 \\
14 \cdot 7 \\
17 \cdot 2 \\
19 \cdot 9 \\
23 \cdot 2 \\
21 \cdot 2 \\
24 \cdot 8\end{array}$ & $\begin{array}{c}6-8 \\
16-20 \\
23 \\
24-24 \\
25-27 \\
29-31 \\
32-33 \\
34-36 \\
38-39\end{array}$ & $\begin{array}{r}7 \cdot 0 \\
18 \cdot 6 \\
23 \cdot 0 \\
24 \cdot 0 \\
26 \cdot 0 \\
29 \cdot 7 \\
32 \cdot 8 \\
35 \cdot 0 \\
38 \cdot 3\end{array}$ \\
\hline $\begin{array}{l}\text { Sepia } \\
\text { sub- } \\
\text { aculeata }\end{array}$ & $\begin{array}{r}16 \\
8 \\
2 \\
2 \\
19 \\
2 \\
6\end{array}$ & $\begin{array}{c}0 \\
27-29 \\
31 \\
32-33 \\
54-63 \\
66-75 \\
109-114\end{array}$ & $\begin{array}{r}5 \cdot 11-7 \cdot 59 \\
17 \cdot 4-24 \cdot 2 \\
24 \cdot 1-26 \cdot 1 \\
24 \cdot 2-24 \cdot 6 \\
42 \cdot 0-60 \cdot 0 \\
56 \cdot 5-64 \cdot 0 \\
134-155\end{array}$ & $\begin{array}{r}5 \cdot 80 \\
21 \cdot 7 \\
25 \cdot 1 \\
24 \cdot 4 \\
49 \cdot 8 \\
60 \cdot 3 \\
142 \cdot 4\end{array}$ & $\begin{array}{c}7-9 \\
27-30 \\
31-31 \\
32-33 \\
54-64 \\
68-71 \\
108-112\end{array}$ & $\begin{array}{r}7 \cdot 8 \\
28 \cdot 3 \\
31 \cdot 0 \\
32 \cdot 5 \\
59 \cdot 1 \\
69 \cdot 5 \\
110 \cdot 0\end{array}$ \\
\hline $\begin{array}{l}\text { Sepiella } \\
\text { main- } \\
\text { droni }\end{array}$ & $\begin{array}{r}10 \\
29 \\
1 \\
1 \\
3 \\
3 \\
18 \\
8\end{array}$ & $\begin{array}{c}0 \\
21-27 \\
40-45 \\
48 \\
50-52 \\
54 \\
94-100 \\
127-133\end{array}$ & $\begin{array}{c}3 \cdot 04-3 \cdot 17 \\
12 \cdot 0-16 \cdot 2 \\
33 \cdot 0 \\
35 \cdot 8 \\
51 \cdot 2-56 \cdot 0 \\
45 \cdot 2-46 \cdot 2 \\
68 \cdot 5-86 \cdot 5 \\
94 \cdot 0-105 \cdot 0\end{array}$ & \begin{tabular}{r|}
$3 \cdot 14$ \\
$14 \cdot 2$ \\
$33 \cdot 0$ \\
$35 \cdot 8$ \\
$53 \cdot 5$ \\
$45 \cdot 4$ \\
$78 \cdot 7$ \\
$97 \cdot 8$
\end{tabular} & \begin{tabular}{l}
\multicolumn{1}{c}{$7-8$} \\
$8^{*}+21-28$ \\
$8^{*}+43$ \\
$8^{*}+48$ \\
$8^{*}+52-54$ \\
$8^{*}+54-54$ \\
$? \dagger+88-98$ \\
$? \dagger+90-100$
\end{tabular} & $\begin{array}{l}\quad 8 \cdot 0 \\
8^{*}+25 \\
8^{*}+43 \\
8^{*}+48 \\
8^{*}+53 \cdot 3 \\
8^{*}+54 \\
? \dagger+92 \cdot 1 \\
?++95 \cdot 5\end{array}$ \\
\hline
\end{tabular}

* The original mean number of stripe-line of the shell in the newly hatched Sepiella maindroni.

$\dagger$ Since the rear end of the shell was broken, the number of stripe-lines could not be counted exactly.

temperature of the water, etc. Table 1 shows the relation between the day-age and the number of stripe-lines for three species of cuttlefishes (Sepia esculenta Hoyle, Sepia subaculeata Sasaki and Sepiella maindroni de Rochebrune) reared undor sufficient foeding and environmental conditions at a water temperature of $19^{\circ}-30^{\circ} \mathrm{C}$. As with Sepia esculenta and Sepia subaculeata, the number of stripe-lines, including those observable at the time of hatching, approximates well to age in days; in Sepiella maindroni, the number is equal to the age in days plus the lines at the time of having been hatched. In other words, it can be said that the shell stripe-lines are formed at the rate of one each day. Between Sepia esculenta or Sepia subaculeata and Sepiella maindroni, however, there is a difference in periodicity of stripe-line formation: the Sepiella maindroni is seen to start forming its stripe-lines at the rate of one per day from the very date of hatching, whereas the other two species are presumed to be dull in their stripe-line formation at the earlier period after hatching. Noteworthy in this connexion is that the resistance against fasting of Sepiella maindroni is 6-7 days, whereas it is 10-11 days in Sepia esculenta and 12-15 days in Sepia subaculeata.

Table 1 gives results obtained under sufficient nutritive and environmental conditions at a water temperature of $19^{\circ}-30^{\circ} \mathrm{C}$. When amount of food is insufficient or feeding does not go smoothly owing to unfavourable ehanges in the sea-water for rearing, the formation of stripe-pattern becomes disturbed and the periodicity of one stripe-line per day is no longer exact. With insufficient foeding especially, the stripe-lines either do not appear or are indistinct with a reduced distance between each. The locular index for this sort of shell is likely to be decreasing. The shell locular index of the cuttlefishes is one of the most significant characteristics for diagnosis of species, so it must be recognized that this characteristic within a somewhat wider range, depending on conditions for growth, varies.

The fact that the number of stripe-lines for Sepiella maindroni which were reared for 127-133 days or until October 31 averages +95.5 (Table 1 ) is thought to be ascribable to the lowering of the water temperature to below $19^{\circ} \mathrm{C}$ during mid-October and afterwards, that is, to the consequent disturbance of the periodicity of formation of the stripe-line.

The shell stripe-line of cuttlefishes is therefore shown to be formed one per day as a rule under good conditions of nourishment, but this does not hold in cases where the nutritive and environment conditions become disturbed so that physiological periodicity is upset.

Department of Marine Biology,

SANG Chot

Fisheries College, Pusan University, Pusan, South Korea.

1 Kobayashi, S., and Watanabe, T., Studies on the Pearl, 120, 234 (1960) (in Japanese).

${ }^{2}$ Appellöf, A., Kongl. Svenska Vet. Akad. Handl., 25, 1 (1893).

3 Naef, A., Fauna u. Flora d. Golfes $v$. Neapel, 35, Cephalopoden II, 226 (1928).

- Yasuda, J., Bull. Jap. Soc. Sci. Fish., 16, 350 (1951) (in Japanese).

'Yagi, T., Bull. Jap. Soc. Sci. Fish., 26, 646 (1960) (in Japanese).

'Hoyle, W. E., Rep. Sci. Voy. Challenger, Zool., 16, 123 (1886).

\section{Rearing of Cuttlefishes and Squids}

WE have succeeded (through improving the feed during the earlier stages after hatching) in rearing three species of the cuttlefish (Sepia esculenta Hoyle, Sepia subaculeata Sasaki and Sepiella maindroni de Rochebrune) and two species of the squid (Sepioteuthis lessoniana Lesson and Euprymna beryii Sasaki) ${ }^{1}$. The main points to note in rearing these animals are as follows :

Great care should be taken of eggs over a fairly long period until hatching. The vital point in the care of eggs is always to arrange that they are in contact with fresh-water, thus preventing the lowering in salinity of the storage sea-water.

If the eggs are exposed to too much light, diatoms or green algae tend to adhere to their surface, thus affecting adversely the development of the eggs. Eggs are better kept in the dark.

The five species of the cuttlefish and the squid mentioned hore start fooding 16-48 h after hatching.

At the earlier stages, when about 2-10 mm long, considerable motility, though not too much, should be allowed. Suitable food are Mysis, larvæ of the shrimp and other small crustacea.

A glass water tank is best for rearing. Flowing seawater containing dissolved oxygen at saturation point encourages feeding.

Having grown to $20 \mathrm{~mm}$ mantle-length (four species except Euprymna beryii achieve a mantle-length of $20 \mathrm{~mm}$ in about 30 days after hatching), the animals begin to prey on small-sized shrimps or fishes.

Following these requirements, 80 per cent survival can be expected, and provided that the supply of food is satisfactory even after the animals begin to prey on largesized food, they may reach adult size 3-4 months after hatching.

\section{Sang ChoE}

Department of Marine Biology, Fisheries College,

University of Pusan, South Korea.

Department of Fisheries,

Faculty of Agriculture,

University of Tokyo.

${ }^{1}$ Ohshima, Y., and Choe, S., Bull. Jap. Soc. Sci. Fish., 27,979 (1961) (in Japanese). Choe, S., and Ohshima, Y., Jap. J. Malacology, 21, 462 (1961) (in Japanese).

\section{Estimation of Dry-Matter Intake in Wild Herbivores}

For some years now, I have been studying nutrition in the wallaby, Setonix brachyurus, on Rottnest Island, Western Australia. A technique ${ }^{1}$ was developed for estimating the relative abundance of various food items in the diet. To convert these data to absolute quantities, total daily intake of dry matter was required. The methods at present used in estimating dry-matter intake by freely 